\title{
COVID - 19 NO BRASIL: o que se espera para população subalternizada?
}

\author{
COVID - 19 IN BRAZIL: what is expected for the subaltern population? \\ COVID - 19 EN BRASIL: ¿qué se espera para la población subalterna?
}

\author{
Yuri Miguel Macedo ${ }^{i}$ \\ Joaquim Lemos Ornellas ${ }^{\text {ii }}$ \\ Helder Freitas do Bomfim ${ }^{\text {iii }}$
}

\begin{abstract}
Resumo: O presente texto visa de forma sistêmica e clássica conceituar o coronavírus (COVID-19), seguindo a proposta analisa os casos de infecção nos países Brasil e Itália, afim de obter resultados que possam ser significantes aos processos de quarentena adquirido pelos ambos países, por meio de uma revisão literária. A base de coleta de dados é a European Centre for Disease Prevention and Control. Após a análise dos dados coletados na base, foi pensado em como as políticas públicas exterminam os sujeitos subalternizados, onde será colocado em xeque a população preta-pobre-periférica do Brasil para corroborar as consequências sociais e efetivas, do cerceamento de direitos dos cidadãos brasileiros.
\end{abstract}

Abstract: This text aims in a systemic and classic way to conceptualize the coronavirus (COVID-19),
following the proposal analyzes the cases of infection in the countries Brazil and Italy, in order to
obtain results that may be significant to the quarantine processes acquired by both countries, through
a literary review. The data collection base is the European Center for Disease Prevention and Control. After
analyzing the data collected at the base, it was thought about how public policies exterminate
subordinated subjects, where the black-poor-peripheral population of Brazil will be put in check to
corroborate the social and effective consequences of the restriction of the rights of Brazilian citizens.

Resumen: Este texto tiene como objetivo una forma sistémica y clásica de conceptualizar el coronavirus (COVID-19), luego de que la propuesta analiza los casos de infección en los países de Brasil e Italia, a fin de obtener resultados que puedan ser significativos para los procesos de cuarentena adquiridos por ambos países., a través de una revisión literaria. La base de recopilación de datos es el Centro Europeo para la Prevención y el Control de Enfermedades. Después de analizar los datos recopilados en la base, se pensó en cómo las políticas públicas exterminan a los sujetos subordinados, donde la población negra-pobre-periférica de Brasil será controlada para corroborar las consecuencias sociales y efectivas de la restricción de los derechos de los ciudadanos brasileños.

Palavras-chave: COVID-19; Brasil; Subalternizados.

Keywords: COVID-19; Brazil; Subalternated.

Palabras claves: COVID-19; Brasil; Subalterno.

a A citação anterior ALMEIDA; LEÃO; BARROS, 2020 foi substituído por esse referencial MAIER; BROCKMANN, 2020 devido ao equívoco de um dos autores que estava em processo de uma escrita conjunta, o mesmo se responsabiliza pelos equívocos de citação e se põe à disposição para maiores informações. yurimacedo@csc.ufsb.edu.br ISSN 2675-1291| DOI: http://dx.doi.org/10.5935/encantar.v2.0001

Revista Encantar - Educação, Cultura e Sociedade - Bom Jesus da Lapa, v. 2, p. 01-10, jan./dez. 2020 


\section{CORONAVÍrus (CORVID-19)}

Coronavírus é uma família de vírus que causam infecções respiratórias, no caso da pandemia desse novo agente, foi descoberto em 31 de dezembro de 2019 em Wuhan na China, $\mathrm{O}$ vírus atual faz que os portadores deles tenham a doença chamada de coronavírus (COVID-19). Os primeiros coronavírus humanos foram destacados pela primeira vez em 1937, no entanto, foi em 1965 que o vírus foi descrito como coronavírus, em decorrência do perfil na microscópica, assemelhando-se a uma coroa.

A maioria das pessoas se infecta com os coronavírus comuns ao longo da vida, sendo as crianças pequenas mais propensas a se infectarem com o tipo mais comum do vírus. Os coronavírus mais comuns que infectam humanos são o alpha coronavírus 229E e NL63 e beta coronavírus OC43, HKU1.

Com o surgimento da pandemia do coronavírus por todo o mundo iniciando o ano de 2020, é necessário repensar desde quando esse vírus está presente na sociedade. E para isso, será aportado desde quando aparece o COVID nos estudos científicos no mundo. Alguns estudos foram encontrados sobre o coronavírus, os que se destacaram foram: "Episodic Evolution Mediates Interspecies Transfer of a Murine Coronavirus", escrito por Baric RS, Yount B, Hensley L, Peel SA, Chen W. em 1997; “An Outbreak of Coronavirus OC43 Respiratory Infection in Normandy, France" escrito em 2003 por Astrid Vabret, Thomas Mourez, Stéphanie Gouarin, Joëlle Petitjean e François Freymuth, que estudaram o surto de infecção por HCoV OC43 na Normandia, França, em fevereiro e março de 2001.;

De acordo com Vabret et al. (2003), o vírus da família Coronaviridae, são RNA vírus de filamento único e senso positivo e não são causa de doença grave em humanos. Eram conhecidos dois diferentes coronavírus humanos: 229E e OC49, ambos causam um resfriado comum, podendo, eventualmente, causar doença respiratória baixa. Epidemias causadas por coronavírus são desconhecidas, mas surtos de doença respiratória baixa, semelhantes, até certo ponto, à atual pandemia, não são totalmente desconhecidos.

Diferentes coronavírus causam diversas doenças em animais desde a peritonite infecciosa felina, a primeira das doenças causadas por coronavírus a ser descrita já em 1912. Foi apenas em 1937 que o primeiro coronavírus foi isolado, de galinhas, e somente em

a A citação anterior ALMEIDA; LEÃO; BARROS, 2020 foi substituído por esse referencial MAIER; BROCKMANN, 2020 devido ao equívoco de um dos autores que estava em processo de uma escrita conjunta, o mesmo se responsabiliza pelos equívocos de citação e se põe à disposição para maiores informações. yurimacedo@csc.ufsb.edu.br ISSN 2675-1291 | DOI: http://dx.doi.org/10.5935/encantar.v2.0001

Revista Encantar - Educação, Cultura e Sociedade - Bom Jesus da Lapa, v. 2, p. 01-10, jan./dez. 2020 
meados da década de 1960 é que seu papel em doença humana foi reconhecido. (Hsiang's, 1991)

Apesar de não ter seu RNA segmentado como os vírus da influenza, os coronavírus são sujeitos a frequentes mutações, razão pela qual o surgimento de um novo coronavírus não é causa para espanto. Aliás, os coronavírus há muito vêm sendo usados como modelo para a investigação de mutações que permitem o salto de espécie. (Baric et al., 1997, 1999)

Doenças infecciosas emergentes não são fruto de paranoias, ocorrem e veem ocorrendo a milhares de anos, por exemplo temos: peste bubônica, cólera Eltor, gripe espanhola, AIDS.

É necessário lembrar que em 1894, teve início em Hong Kong a terceira pandemia de peste bubônica, foram necessários cinco anos para que chegasse ao Brasil. Desta vez, bastaram alguns dias para a chegada dos primeiros casos suspeitos.

Essa deve ser considerada como a pandemia contemporânea, pois, assola e faz que inúmeras nações sejam cessadas e fortes na luta contra o vírus. O CORVID-19, veio para expor que existe sim uma globalização do vírus e que ainda dá tempo das nações igual ao Brasil repensar as políticas públicas na saúde para não extermínio da sua minoria. Trata-se, portanto, de uma necessidade premeditada, não de uma fantasia ou fetiche governamental.

\section{CoRONAVÍRUS NA ITÁLIA}

No dia 31 de janeiro de 2020 a Organização Mundial da Saúde (OMS) declara eleva a situação do COVID-19 à emergência internacional, no dia seguinte a Itália divulga seus três primeiros casos de corona vírus no país, suspende os voos vindos da China e declara emergência nacional. Após 22 dias desde a divulgação dos primeiros positivos no país a Itália atinge 17 casos confirmados no país.

A preocupação com o vírus está no seu poder de crescimento exponencial (MAIER; BROCKMANN, 2020ª). Teoricamente no dia um há uma pessoa infectada, no dia seguinte são duas pessoas. No terceiro dia serão quatro infectados. No quarto dia oito infectados e assim seletivamente. No decimo quinto dia haverão 16.384 infectados.

A esse respeito cabe analisar a estrutura etária da Itália e os grupos de risco associados ao COVID-19. Segundo Chen (et al., 2020) o grupo mais vulnerável ao vírus são os homens com mais de 50 anos e com presença de comorbidades. Nesses casos a infecção viral pode evoluir para quadros de doenças respiratórias fatais ou insuficiência respiratória aguda.

a A citação anterior ALMEIDA; LEÃO; BARROS, 2020 foi substituído por esse referencial MAIER; BROCKMANN, 2020 devido ao equívoco de um dos autores que estava em processo de uma escrita conjunta, o mesmo se responsabiliza pelos equívocos de citação e se põe à disposição para maiores informações. yurimacedo@csc.ufsb.edu.br ISSN 2675-1291 | DOI: http://dx.doi.org/10.5935/encantar.v2.0001

Revista Encantar - Educação, Cultura e Sociedade - Bom Jesus da Lapa, v. 2, p. 01-10, jan./dez. 2020 
A Itália possui 62.402 .659 habitantes, destes $38 \%$ da população possui 55 anos ou mais, 10.193.295 pessoas da população italiana enquadram-se no perfil etário do novo vírus, essas informações também são uteis para pensar em como deverá proceder a propagação do vírus. Segundo dados coletados do European Centre for Disease Prevention and Control (2020), 31 dias após o caso inicial de COVID-19 no país, a Itália apresenta 1.128 casos, dia 03/03 os casos oficiais aumentam para 1.835 .

No quadragésimo dia desde a aparição do primeiro caso no país, a Itália decreta quarentena nacional, ultrapassando 7 mil casos confirmados. Dois dias após a quarentena nacional todos os bares e restaurantes são fechados (12.462 casos). É possível verificar no gráfico a seguir que mesmo após a imposição da quarentena obrigatória a quantidade de casos diários continua a aumentar. No seu $53^{\circ}$ dia, o número de casos confirmados na Itália atingiu aproximadamente 59 mil casos e 5.476 mortos, diante do avanço do vírus, o governo italiano decide fechar todos os serviços não essenciais no país.

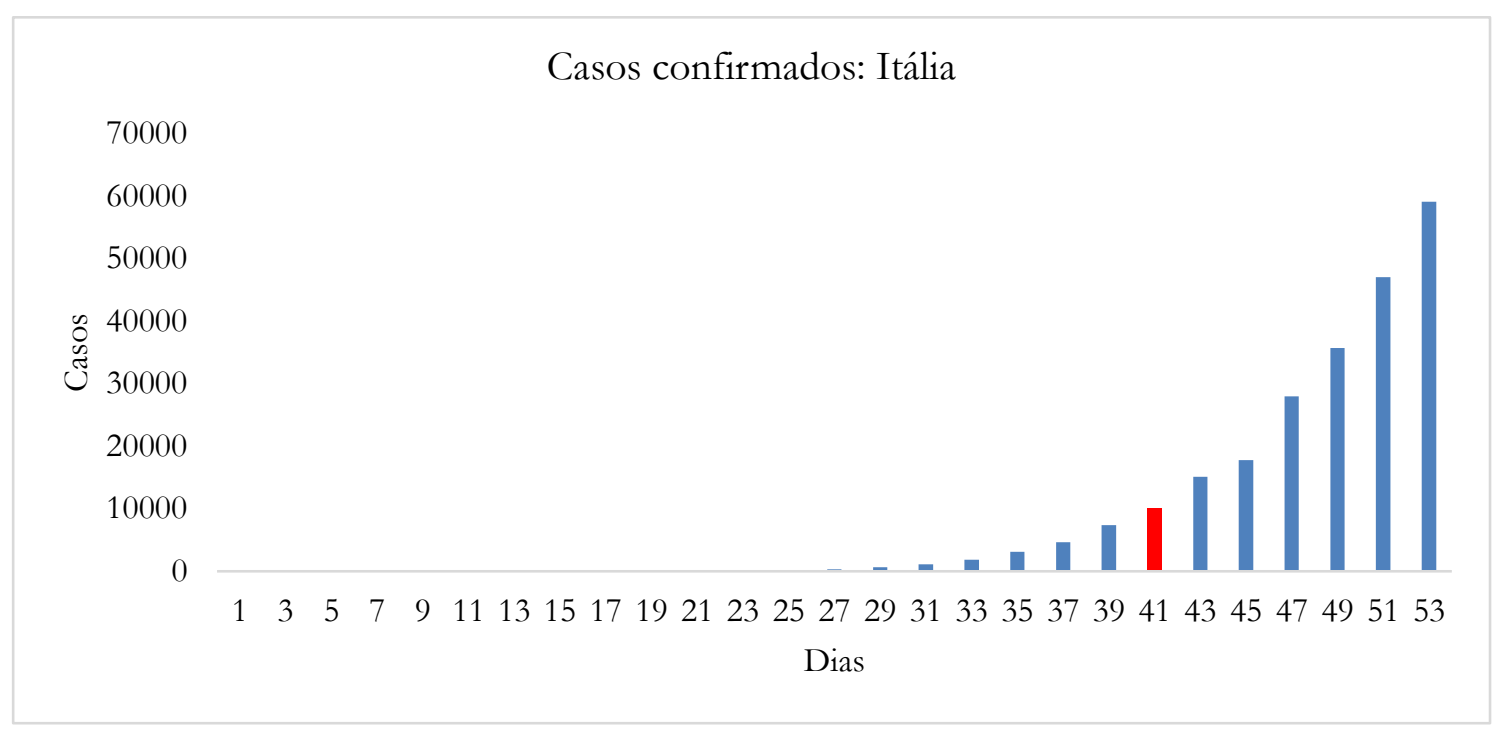

a A citação anterior ALMEIDA; LEÃO; BARROS, 2020 foi substituído por esse referencial MAIER; BROCKMANN, 2020 devido ao equívoco de um dos autores que estava em processo de uma escrita conjunta, o mesmo se responsabiliza pelos equívocos de citação e se põe à disposição para maiores informações. yurimacedo@csc.ufsb.edu.br ISSN 2675-1291 | DOI: http://dx.doi.org/10.5935/encantar.v2.0001

Revista Encantar - Educação, Cultura e Sociedade - Bom Jesus da Lapa, v. 2, p. 01-10, jan./dez. 2020 


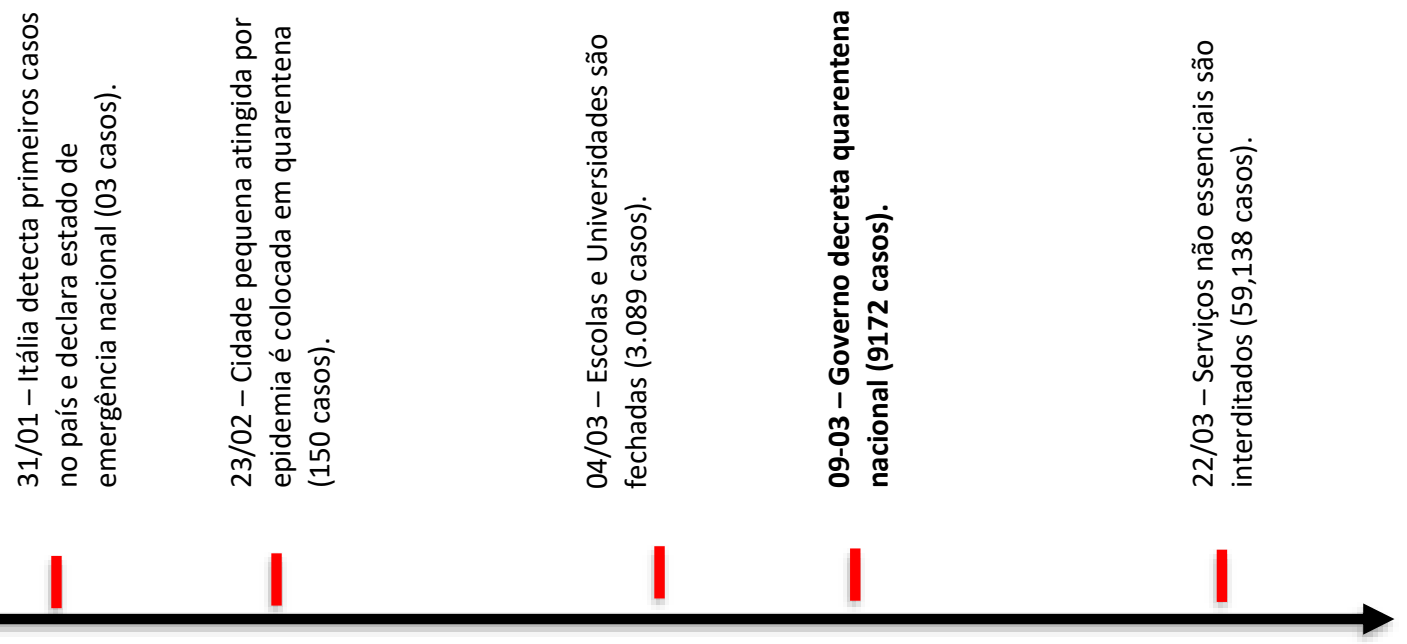

Linha temporal - Itália. Fonte: Autores (2020)

\section{Coronavírus NO BRASIL}

O primeiro teste positivo para COVID-19 no país aparece em 26 de fevereiro de 2020 importado por um paulistano que havia recentemente visitado a Itália. Cinco dias após o primeiro caso, outro caso positivo é confirmado no país e em apenas 11 dias a soma dos casos confirmados atinge 25 pessoas.

A população brasileira é estimada entre 211 milhões de habitantes (IBGE, 2020), destes $8 \%$ são homens que se enquadram no perfil etário da doença contudo novos casos da doença avançam rapidamente no país. Enquanto a Itália decreta quarentena nacional 10 dias após os primeiros casos positivos, a quarentena é regulamentada pelo Ministério da Saúde 16 dias após a detecção do primeiro caso, totalizando mais de 100 casos confirmados.

a A citação anterior ALMEIDA; LEÃO; BARROS, 2020 foi substituído por esse referencial MAIER; BROCKMANN, 2020 devido ao equívoco de um dos autores que estava em processo de uma escrita conjunta, o mesmo se responsabiliza pelos equívocos de citação e se põe à disposição para maiores informações. yurimacedo@csc.ufsb.edu.br 


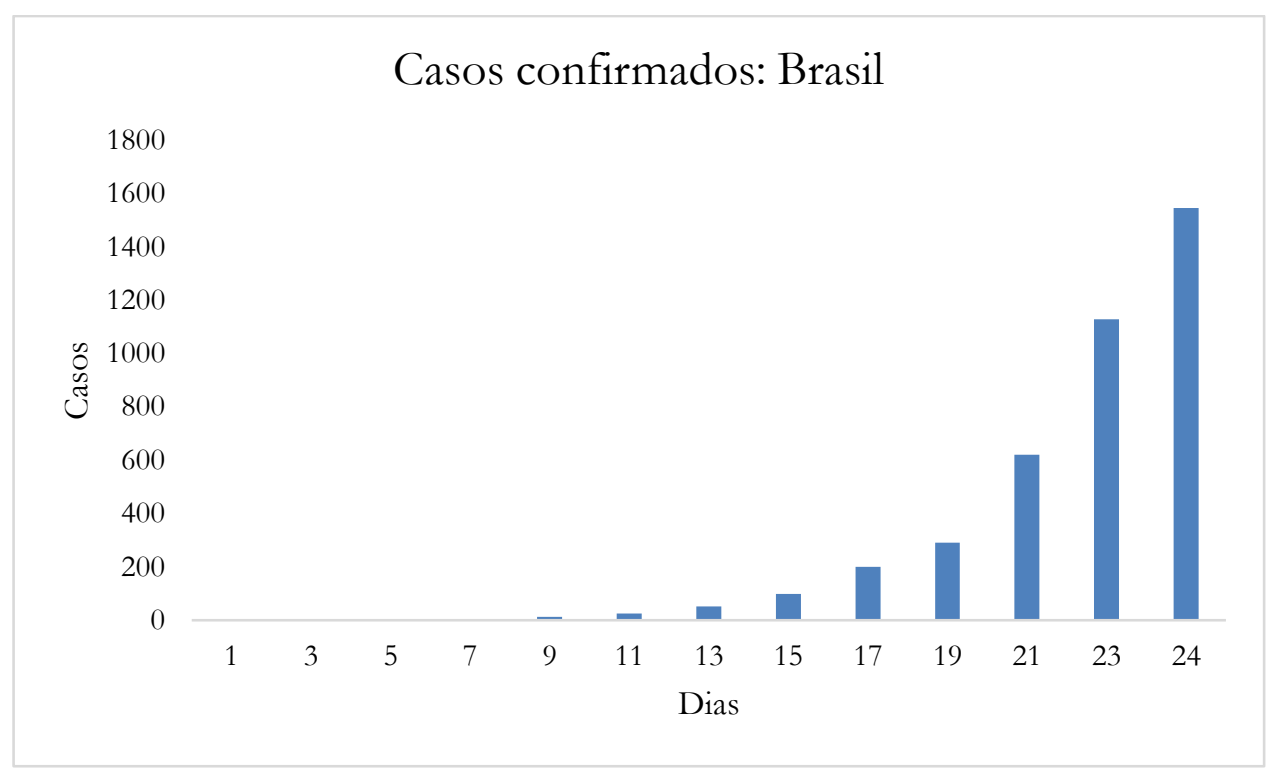

Casos Confirmados - Brasil. Fonte: Autores (2020)

Segundo o Observatório COVID-19BR (2020) a atual taxa de duplicação de infectados dados as medidas de contenção (23/03) variam entre 2,4 e 2,8 dias. Seguindo aproximadamente o padrão de propagação da Itália e não diminuindo mesmo com as medidas de contenção, o Brasil já ultrapassa a quantidade da Itália em comparação em seu $23^{\circ}$ dia com 1128 casos confirmados contra 17 dos italianos. Segundo estimativas dos autores supracitados, caso vírus continue seguindo essa taxa de infecção, espera-se que até 28/03 tenham entre 6.591 e 8.473 casos em todo país. 


\title{
Políticas de EXTERMínIO DA POPULAÇÃo PRETA-POBRE-PERIFÉRICA NO BRASIL
}

\begin{abstract}
As camadas mais baixas da sociedade constituídas pelos modos específicos de exclusão dos mercados da representação política e legal, e da possibilidade de se tornarem membros plenos no estrado social dominante, esse são os subalternos. (Spivak, 2010, pag. 13-14)
\end{abstract}

Os processos de redução de infecção em todos os lugares do mundo, se dá pelo isolamento e quarentena da sociedade, higienização e medidas para pormenorizar as contaminações. No Brasil, foi adotado pelo Ministério da Saúde -MS (2020) as seguintes medidas: Vigilância, Suporte laboratorial, Medidas de controle de infecção, Assistência, Assistência farmacêutica, Vigilância Sanitária - Medidas de saúde em pontos de entrada, Comunicação de risco e Gestão. E ambos estão pautados inicialmente na higienização das mãos com água e sabão e/ou álcool em gel 70\%.

Sobre o processo de prevenção, existem as orientações que o MS (2020), indicou que é: -Lave as mãos com água e sabão ou use álcool em gel; -Cubra o nariz e boca ao espirrar ou tossir; - Evite aglomerações se estiver doente; -Mantenha os ambientes bem ventilados; Não compartilhe objetos pessoais. E seguindo essas orientações, a possibilidade de infectado com o COVID-19, é diminuída a chance.

Diante das orientações apresentadas podemos observar os seguintes aspectos, para que a população possa lavar as mãos e talvez tenha sabão ou álcool em gel 70\%, são necessários políticas de saneamento básico e abastecimento de água. Que outrora, corresponde de acordo com o Sistema Nacional de Informações sobre Saneamento - SNIS, no ano de 2018, que a média da população que possui esgotamento sanitário é de 53,2\% média de 107,5 milhões de pessoas, sendo que, de suas totalidades, as regiões sudeste com $79,2 \%$ possui esgotamento sanitário, seguindo da região Centro-Oeste com 52,9\%, depois a região sul com $45,2 \%$, penúltimo o nordeste com $28 \%$ e por fim o norte do Brasil com 10,5\% (Brasil, 2018).

Em relação a abastecimento de água no Brasil, e de acordo com o SNIS(2018), a população que tem acesso a água é na média de 169,1 milhões de pessoas, ou seja, 83,6\%, distribuído com $91 \%$ na região sudeste, $90,2 \%$ na região sul, $89 \%$ na região Centro-oeste, $74,2 \%$ na região nordeste e $57,1 \%$ da região norte do país.

a A citação anterior ALMEIDA; LEÃO; BARROS, 2020 foi substituído por esse referencial MAIER; BROCKMANN, 2020 devido ao equívoco de um dos autores que estava em processo de uma escrita conjunta, o mesmo se responsabiliza pelos equívocos de citação e se põe à disposição para maiores informações. yurimacedo@csc.ufsb.edu.br ISSN 2675-1291 | DOI: http://dx.doi.org/10.5935/encantar.v2.0001

Revista Encantar - Educação, Cultura e Sociedade - Bom Jesus da Lapa, v. 2, p. 01-10, jan./dez. 2020 
Além das medidas que precisam basicamente de esgotamentos e abastecimento de água, é necessário repensar esses serviços públicos em manutenção do acesso a todos e principalmente na prevenção do COVID-19. É preciso, analisar sobre os processos que envolvem o capital e seus atores, ou seja, ver como a classe trabalhadora que é a maioria no país, pode ser cerceado o direito de compra, com a perda salarial, desemprego e o não recebimento de salários que é proposto pelo Governo Federal?

O que se tange sobre as orientações para evitar aglomerações, o que é questionável e que se põe em análise são as periferias e favelas ao longo do Brasil que de acordo com Ivo (2010),

[...] as periferias se constituem como lugares híbridos e heterogêneos de um cotidiano compartilhado por sujeitos que vivem na adversidade e na busca por justiça social e por direitos sociais e direitos sobre a cidade, como o acesso à moradia, à saúde, ao transporte, à educação e ao consumo cultural, que interagem e se mesclam com a cidade normatizada, racional, "legitimada", ultrapassando velhas noções morais de culpabilidade da pobreza ou de territórios de riscos, que podem sugerir sentidos estigmatizados de criminalização da pobreza.

Políticas Públicas supracitadas, traz em si consequências positivas para o bem estar social e a saúde da população que tem o Sistema Único de Saúde a sua única saída para melhoria de vida. E para isso, Leoneti et.a. (2011), corrobora que, as políticas públicas voltadas para a melhoria das condições de saneamento básico das comunidades são eficazes para diminuir a mortalidade [...] e a doenças relacionadas às condições do ambiente em que se vive. As periferias, ou favelas, de acordo com Jodelet (1998, p.48), está referida àqueles que, marcados com o selo da diferença, seja ela física (cor, raça, deficiência, etc) ou ligada a uma pertença de grupo (nacional, étnico, comunitário, religioso, etc), se distinguem no seio de um conjunto social ou cultural e podem aí ser considerados como fonte de mal-estar ou de ameaça.

A população nas favelas cresceu vertiginosamente nas últimas décadas, principalmente a partir do final dos anos 50. Atualmente, temos uma diminuição dos índices de pobreza, camuflados pelos critérios de avaliação. Apesar de o favelado de hoje ter televisão, geladeira, fogão, vídeocassete e até microondas, essa melhora na qualidade de vida esbarra na inércia da vivência da exclusão durante gerações. A falta de perspectiva de futuro e de empregos para as gerações mais novas retrata uma subsequente reprodução da pobreza e da exclusão social (VERAS, 1999).

Veras, em sua afirmação traz à tona a realidade que é vivida nas favelas e periferias, porém muito além de políticas e projetos de governos, são necessários para a manutenção

a A citação anterior ALMEIDA; LEÃO; BARROS, 2020 foi substituído por esse referencial MAIER; BROCKMANN, 2020 devido ao equívoco de um dos autores que estava em processo de uma escrita conjunta, o mesmo se responsabiliza pelos equívocos de citação e se põe à disposição para maiores informações. yurimacedo@csc.ufsb.edu.br 
desses guetos princípios equânimes de distribuição de renda, trabalho, lazer, educação, saúde e saneamento básico. Que é direito de todos, e obrigação do Estado.

\section{CONSIDERAÇÕES FINAIS}

Diante dos dados apresentados dos infectados e mortos do Brasil e Itália é possível, pensar quais destinos estão sendo traçados pelo Estado para a minoria, sendo em sua maioria no Brasil preta-pobre-periférica.

Tomando uma proporção de 4 países: China (Ásia), Itália (Europa), Paquistão (Ásia) e Nigéria(África), no dia 23 de março de 2020, ambos não escolhido por acaso, a China como o primeiro país em apresentar sintomas do COVID-19, apresenta uma população de 1.394.550.000 de pessoas e o número de infectados alcançam 0,005854\% do total da população. Seguindo pela Itália, que foi escolhido por ter a curva de infectados parecido com a do Brasil, que tem uma população de 68.480 .000 pessoas e o número de casos está em média de 0,0863\% da população. Já no caso do Paquistão e Nigéria, foram escolhidos por apresentar a população próxima ao número de habitantes do Brasil. Para tanto, o Paquistão, possui 216.000.000 habitantes e sua média de casos confirmados no país foi de 0,0000036296\% da população, paralelamente a isso a Nigéria com 193.392.517 de habitantes apresentou a média de casos confirmados de COVID-19 em 0,0000015512\% da população.

Para o mês de abril de 2020 onde se espera o pico dos números de casos o Brasil pode esperar as seguintes situações: Situação $1=209.300 .000 * 0,005854 \%=1.225 .242 \mathrm{em}$ média de infectados; Situação $2=209.300 .000 * 0,0863 \%=\mathbf{1 8 . 0 6 2 . 5 9 0 ~ e m ~ m e ́ d i a ~ d e ~}$ infectados; Situação $3=209.300 .000 * 0,0000036296 \%=759$ em média de infectados e Situação $4=209.300 .000 * 0,0000015512 \%=324$ em média de infectados. Nas situações 3 e 4, já foram descartados essa possibilidade, pois, no dia 24 de março de 2020, já estavam com 25 mortos e 1.546 casos confirmados, no vigésimo quarto dia da quarentena.

É necessário mais que declarar Estado mínimo, é necessário repensar as ações de Esgotamentos Sanitários nessas áreas subalternizadas; Abastecimento de água como condição mínima a todos os cidadãos; Acesso à educação gratuita, pública e de qualidade; políticas de promoção saúde públicas. Pois, é nas instituições públicas e nas universidades que se produz mais de $90 \%$ da ciência no Brasil.

Por fim, já se sabe que caminhos se levam a política de estado no Brasil, que por via pensa no capital como única saída, sucateando os direitos e conquistas dos cidadãos,

a A citação anterior ALMEIDA; LEÃO; BARROS, 2020 foi substituído por esse referencial MAIER; BROCKMANN, 2020 devido ao equívoco de um dos autores que estava em processo de uma escrita conjunta, o mesmo se responsabiliza pelos equívocos de citação e se põe à disposição para maiores informações. yurimacedo@csc.ufsb.edu.br 
trabalhadores e trabalhadoras que estão nas favelas, periferias e guetos. O que deve ainda ser seguido é a quarentena, como prevenção social para não alcançar as situações supra. Nos resta a fé e pedidos a Deus, a Kavungo, a Obaluaie, a Ajansu, a Azoani e todos os Deuses da terra, saúde para nós, e para todos.

\section{REFERÊNCIAS}

BARIC RS, SULLIVAN E, HENSLEY L, YOUNT B, CHEN W. Persistent infection promotes cross-species transmissibility of mouse hepatitis virus. J Virol 1999;73:638-49.

BARIC RS, YOUNT B, HENSLEY L, PEEL SA, CHEN W. Episodic evolution mediates interspecies transfer of a murine coronavirus. J Virol 1997;71:1946-55.

CHEN, Nanshan et al. Epidemiological and clinical characteristics of 99 cases of 2019 novel coronavirus pneumonia in Wuhan, China: a descriptive study. The Lancet, v. 395, n. 10223, p. $507-513,2020$.

\section{CIA. Central Intelligence Agency. Europe: Italy. Disponível em: https://www.cia.gov/library/publications/the-world-factbook/geos/print it.html. \\ Acesso em: 23 de março de 2020.}

ECDC. European Centre for Disease Prevention and Control. data on the geographic distribution of COVID-19 cases worldwide. Disponível em: https://www.ecdc.europa.eu/en/publications-data/download-todays-data-geographicdistribution-covid-19-cases-worldwide. Acesso em: 23 de março de 2020.

HSIANG'S M. from: http://www.stanford.edu/group/virus/1999/mhsiang/corona.html [2003 abr 20].

IBGE. Instituto Brasileiro de geografia e Estatística. População, 2020.

IVO, Anete BL. Uma periferia em debate: questões teóricas e de pesquisa. Cafajeste. CRH, Salvador, v. 23, n. 58, p. 15 a 15 de abril de 2010. Disponível em $<$ http:/ /www.scielo.br/scielo.php?script $=$ sci arttext\&pid $=$ S0103-

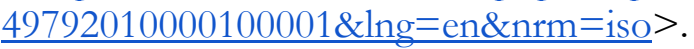

JODELET, D. (1998). A alteridade como processo e produto psicossocial. Em A. Arruda (Org.), Representando a alteridade (pp. 47-67). Petrópolis, RJ: Vozes.

LEONETI, Alexandre Bevilacqua; PRADO, Eliana Leão do; OLIVEIRA, Sonia Valle Walter Borges de. Saneamento básico no Brasil: considerações sobre investimentos e sustentabilidade para o século XXI. Rev. Adm. Pública, Rio de Janeiro , v. 45, n. 2, p. 331 348, Apr. 2011 Available from

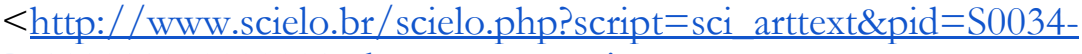

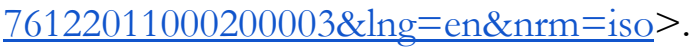


MAIER, Benjamin F.; BROCKMANN, Dirk. Effective containment explains subexponential growth in confirmed cases of recent COVID-19 outbreak in Mainland China. arXiv preprint arXiv:2002.07572, 2020. https://doi.org/10.1101/2020.02.18.20024414

OBSERVATÓRIO COVID-19 BR. 23 de março de 2020, 22:49. Disponível em: https://covid19br.github.io/. Acesso em: 23 de março de 2020.

SPIVAK, Gayatri Chakravorty. Pode o subalterno falar? 1. ed. Trad. Sandra Regina Goulart Almeida; Marcos Pereira Feitosa; André Pereira. Belo Horizonte: Editora da UFMG, 2010.

VABRET A, MOUREZ T, GOUARIN S, PETITJEAN Jl, FREYMUTH F. An outbreak of coronavirus OC43 respiratory infection in Normandy, France. Clin Inf Dis 2003;36:9859. https://doi.org/10.1086/374222

VÉRAS, M. Exclusão social - um problema brasileiro de 500 anos. In: SAWAIA, B. (Org). As artimanhas da exclusão. Petrópolis: Vozes, 1999. p. 27-52.

i Orientado por Eliana Povoas Pereira Estrela Brito no Programa de Pós-Graduação Ensino e Relações ÉtnicoRaciais da Universidade Federal do Sul da Bahia, Porto Seguro, Brasil. Professor Pesquisador do Núcleo de Estudos Afro-Brasileiros da Universidade Federal do Espirito Santo (UFES), Professor no Programa de PósGraduação Lato Sensu Formação de Professores em Letras-Libras na Universidade do Estado da Bahia (UNEB), licenciado em Pedagogia pela Faculdade de Filosofia, Ciências e Letras de Boa Esperança - FABIBE, Especialista em História e Cultura Afro-Brasileira, Especialista em Educação de Jovens e Adultos, atuando principalmente nos seguintes temas: Identidade, Cultura, Classe, Gênero, Educação Inclusiva, Educação, Devoções, Transversalidade, Africanidades e Ancestralidade. Coordenador do Grupo de Pesquisa Educação Transversal (UFES), vice coordenador do Grupo de Pesquisa Erê-Ecoa (UFES) Pesquisador dos grupos: GELPOC (IFBA) ; Políticas de Inclusão e Educação para as Relações Étnico-Raciais (UFES); Invisibilidade Social e Energias Emancipatórias em Direitos Humanos (FDV); Espaços Deliberativos e Governança Pública (UFV/CLACSO) e Educação para as relações étnico-raciais, territorialidades e novas mídias (UFES). Membro da Associação Brasileira de Pesquisadores Negros (ABPN), Associação Nacional de Pós-Graduação e Pesquisa em Educação (ANPED) e Société Internationale d'Ergologie. E-mail: yurimacedo@csc.ufsb.edu.br

ii Orientado por Elfany Reis do Nascimento Lopes no Programa de Pós-Graduação em Ciências e Tecnologias Ambientais da Universidade Federal do Sul da Bahia, Porto Seguro, Brasil. Licenciatura em Biologia pela Universidade Federal do Recôncavo da Bahia - UFRB; Realizou intercâmbio na Universidade de Bayreuth, Alemanha, cursando disciplinas nas áreas de ecologia, clima e serviços ecossistêmicos; Foi bolsista de iniciação científica e estagiário pela Empresa Brasileira de Pesquisa Agropecuária - EMBRAPA; foi estudante do Laboratório de Apoio Diagnóstico em Anemias - LADA, participando como palestrante do Programa Tutorial em Saúde - Sensibilização em Doença Falciforme, focando nos Métodos de Diagnóstico da Doença Falciforme, com o intuito de sensibilizar profissionais de saúde nos municípios circunvizinhos a Cruz das Almas. Atualmente realiza é membro do Laboratório de Ecologia Vegetal e Restauração - LEVRE da UFRB em parceria com a Fundação Vovó do Mangue atuando na restauração, conservação e monitoramento dos manguezais da RESEX Baía do Iguape com ênfase no serviço ecossistêmico de sequestro de carbono e redução das mudanças climáticas. Também realiza trabalhos de ecologia de comunidades na Mata Atlântica e desenvolve atividades de monitoramento com drones e sensoriamento remoto na produção de mapas e ortofotografias. Email: joaquimor_2@hotmail.com

iii Orientado por Iracema Brandão Guimarães no Programa de Pós Graduação em Ciências Sociais da Universidade Federal da Bahia. Mestre em Ciências Sociais pelo Programa de Pós Graduação em Ciências Sociais da Universidade Federal da Bahia. Especialista em Gestão de Projetos, pela Universidade do Estado da Bahia, e formado pelo curso de Ciências Sociais da Faculdade de Filosofia e Ciências Humanas também da Universidade Federal da Bahia. Atualmente é Professor Substituto da Universidade do Estado da Bahia, vinculado ao Departamento de Ciências Humanas e Tecnologias do Campus Bom Jesus da Lapa, coordenador do grupos de pesquisa Ciência e Resistência e desenvolve pesquisas na área da Sociologia Urbana, Movimentos Sociais e Educação, interessando-se principalmente pelos estudos sobre associativismo, política, cultura, projetos urbanos e cidades. Atualmente é um pesquisador vinculado Grupo de Pesquisa CiMov - Cidades e

a A citação anterior ALMEIDA; LEÃO; BARROS, 2020 foi substituído por esse referencial MAIER; BROCKMANN, 2020 devido ao equívoco de um dos autores que estava em processo de uma escrita conjunta, o mesmo se responsabiliza pelos equívocos de citação e se põe à disposição para maiores informações. yurimacedo@csc.ufsb.edu.br ISSN 2675-1291| DOI: http://dx.doi.org/10.5935/encantar.v2.0001

Revista Encantar - Educação, Cultura e Sociedade - Bom Jesus da Lapa, v. 2, p. 01-10, jan./dez. 2020 
Movimentos Centro de Pesquisas de Humanidades - CRH e estudante da linha de pesquisa Trabalho, Classes e Desigualdades do PPGCS da UFBA. E-mail: hfreitas@uneb.br

a A citação anterior ALMEIDA; LEÃO; BARROS, 2020 foi substituído por esse referencial MAIER; BROCKMANN, 2020 devido ao equívoco de um dos autores que estava em processo de uma escrita conjunta, o mesmo se responsabiliza pelos equívocos de citação e se põe à disposição para maiores informações. yurimacedo@csc.ufsb.edu.br ISSN 2675-1291| DOI: http://dx.doi.org/10.5935/encantar.v2.0001

Revista Encantar - Educação, Cultura e Sociedade - Bom Jesus da Lapa, v. 2, p. 01-10, jan./dez. 2020 